\title{
SOBRE A NÃO ARGUMENTALIDADE DE SE EM PORTUGUÊS EUROPEU: COMPARAÇÃO COM O CABOVERDIANO ${ }^{1}$
}

\section{Maria Alexandra Fiéis Fernanda Pratas ${ }^{2}$}

Centro de Linguística da Universidade Nova de Lisboa

Resumo: Com o presente trabalho, pretendemos dar conta da ausência de um morfema de reflexividade do tipo se em Caboverdiano (CV) mostrando como a leitura reflexiva nesses contextos depende das propriedades internas (semânticas) dos predicados. É também nosso objectivo mostrar que a ausência desse morfema em CV e a sua obrigatoriedade em determinados contextos em Português Europeu (PE) se relacionam com diferenças na arquitectura da frase. Esperamos ainda poder apontar uma nova via para o estudo de algumas formas clíticas em $\mathrm{PE}$, nomeadamente no que respeita à distinção entre os clíticos do tipo se (argumentais e não-argumentais). As propostas teóricas da Morfologia Distribuída (HALLE \& MARANTZ, 1993, EMBICK \& NOYER, 2001) enquadram este nosso trabalho comparado, articulando princípios da semântica lexical (estrutura argumental e grelha temática dos predicados), da semântica composicional (interpretação da frase) e restrições de ordem sintáctica (arquitectura da frase) para dar conta de fenómenos que consideramos serem operados no módulo pós-sintáctico, na componente morfofonológica da gramática.

Palavras-chave: Morfema se; semântica lexical e composicional; arquitectura da frase.

\section{Introdução}

Diversos contextos verbais que em PE ocorrem com um clítico reflexivo do tipo se (diferente da expressão anafórica, não clítica, do tipo SELF, a si mesmo), ocorrem em CV sem uma marca morfológica de reflexividade.

1 O presente artigo é uma versão revista da comunicação apresentada no XX Encontro da APL, Lisboa, Outubro 2004, tendo beneficiado dos comentários e sugestões da audiência.

2 Bolseira da Fundação para a Ciência e Tecnologia: SFRH / BD / 11064 / 2002.

3 Variedade de Santiago, com dados recolhidos nas localidades Flamengos, concelho de São Miguel, e Picos de Santa Catarina, concelho de Santa Catarina. 
Este problema não inclui o se-nominativo (um dos casos de $s e$ impessoal, como em Vende-se casas.), de natureza argumental, nem o se-passivo (como em Vendem-se casas.), de natureza quaseargumental (DUARTE, 2001).

(1) Kasas ta bendedu.

Casas TMA vender.PART.PASS

'São vendidas casas.'

(2) Ten kasas pa bende.

Tem casas para vender.

'Há casas à venda.'

Contextos reflexivos:

(3)a. Pedru laba mo.

'O Pedro lavou as mãos.'

b. Pedru laba.

'O Pedro lavou-se.'

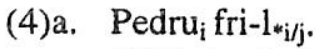

'O Pedro feriu-o'

b. Pedru fri.

'O Pedro feriu-se.'

(5)a. Djon perdi dinheru.

'O João perdeu o dinheiro.'

b. Djon perdi na tenpu.

'O João perdeu-se.'

Seguem-se outros predicados reflexivos, aqui sem a entrada transitiva:

(6) Eder xinta pamodi e bai kumi.

'O Eder sentou-se porque vai comer.'

(7) Irina dja pentia.

'A Irina acaba de se pentear.'

E outros, com os chamados se não-argumentais (ditos $s e$-anticausativo

(8) e se-inerente (9)):

(8)a. Porta abri.

'A porta abriu(-se).'

b. Vidru kebra.

'O vidro partiu(-se)' 
(9) Maria ngana na konta.

'A Maria enganou-se nas contas. ${ }^{4}$

Hipótese 1: o CV (como o inglês) não dispõe destes morfemas no seu léxico, e por isso não pode usá-los (pouco explicativo).

Hipótese 2: na linha do que defendem Levin e Rappaport Hovav (1995), e.o., são as propriedades do âmbito da semântica lexical que permitem dar conta das diferenças encontradas entre alguns predicados, com conseqüências no ordenamento dos constituintes na frase.

Aliás, este é um tipo de variação que é não só intralinguística, mas pode ser verificada de língua para língua. Por exemplo:

(10)a. Jean a brûlé la maison.

'O João queimou a casa.'

b. La maison a brûlé.

'A casa ardeu.' (lit. A casa queimou.)

(11)a. Sortez la voiture du garage.

'Tirem o carro da garagem.' (lit. Saiam o carro da garagem.)

b. Jean est sorti.

'O João saiu.'

c. Il nous a sorti dès lors à peu près toute sa psychologie. (cf. Grévisse, 1993, p. 419)

'Ele saiu-se-nos logo com quase toda a sua psicologia.'

(12)a. Personne ici ne serait capable de me tomber.

'Ninguém aqui seria capaz de me derrubar.' (lit. ...seria capaz de me cair)

b. Jean est tombé.

'O João caiu.'

c. Les gens à cheval doivent avoir tombé le taureau avant d' arriver à cette limite. (cf. Grévisse, Idem.)

'As pessoas a cavalo devem ter derrubado o touro antes de chegar àquele limite.' (lit. ... devem ter caído o touro)

4 Note-se que esta entrada pode admitir redobro em PE - A Maria enganouse a si própria. - e ocorrer em CV com uma anáfora do tipo SELF - Maria ngana si kabesa. -, mas teria uma leitura diferente da apresentada em (9). Em (9), temos um sujeito-Paciente e, neste caso, teríamos um sujeitoAgente. 
Em suma, há verbos com diferentes valores semântico-lexicais associados, e essas diferenças podem ser encontradas quer intralinguisticamente quer entre línguas diferentes, como o $\mathrm{PE}$ e o francês, ambas línguas românicas.

\section{Propostas anteriores}

\subsection{Quanto à ausência do morfema se:}

Segundo Reinhart (1996, 2000, 2001), existe redução lexical em algumas entradas verbais do inglês (como Max washed. - redução do argumento interno -, resultando numa entrada de tipo reflexivo; e Lucie rolled. - redução do argumento externo -, resultando numa entrada de tipo inacusativo $)^{5}$. No entanto, esta análise não explica o caso do PE em que o clítico está presente e é sumariamente assumido como um vestígio do Caso acusativo deixado na operação de redução.

\subsection{Quanto ao morfema se em PE (alguns contextos):}

Segundo Duarte (2001), os clíticos argumentais - pronominais e anáforas -, pelo facto de assumirem referência definida, seriam núcleos de DPs inseridos por Merge em posições $\theta$-marcadas internas a VP:

5 Em Pratas $(2002,2004)$ esta proposta foi aplicada aos dados do CV acima expostos. Ela pretende dar conta da violação, em Max washed. (com leitura 'O Max lavou-se.'), da condição B da Teoria da Reflexividade dos Predicados (REINHART \& REULAND 1993). Recorde-se de que as condições A e B desta teoria, que vêm reformular as condições da Teoria Standard da Ligação (CHOMSKY 1981, 1986), predizem o seguinte:
A. Um predicado sintáctico [apenas V] marcado reflexivamente é reflexivo.
B. Um predicado semântico [pode ser $\mathrm{V}, \mathrm{N}$ ou $\mathrm{P}$ ] reflexivo é marcado reflexivamente.

Em certos contextos, uma preposição ou um nome podem funcionar como predicados semânticos, projectando dois argumentos que, quando coreferentes, requerem a marca de reflexividade. Em (i), temos o exemplo apresentado por Reinhart e Reuland, que mostra a preposição over como predicado semântico. Os exemplos com Ns são mais complexos, daí não caberem no âmbito deste trabalho:

(i) Max rolled the carpet $\mathrm{i}_{\mathrm{i}}$ over $*_{\mathrm{it}_{\mathrm{i}}} / \mathrm{itself}_{\mathrm{i}} / \mathrm{him}$. 


$$
\text { (13) }\left[\mathrm{IP}\left[\mathrm{vp} \mathrm{V} \ldots\left[\mathrm{dp}\left[\mathrm{D}^{0} \mathrm{CL}\right] \ldots\right]\right] /\left[\mathrm{IP}\left[\mathrm{vp}\left[\mathrm{DP}\left[\mathrm{D}^{0} \mathrm{CL}\right] \mathrm{V} \ldots\right]\right]\right.\right.
$$

(DUARTE, 2001, p. 143)

Enquanto isso, os anticausativos e os inerentes (ambos nãoargumentais), sem qualquer estatuto referencial, seriam inseridos por Merge na posição de núcleo funcional Asp, conforme os traços que este contém (traços de incausativização no primeiro caso, e de diátese médio-passiva no segundo):

$$
\text { (14) [IP [DP Os copos } \left.\left.\left.]_{i} \ldots \text { [InacusP [Inacus } s e\right]\left[\mathrm{vP}_{\mathrm{i}}\left[\mathrm{v}^{\cdot} \mathrm{V} \mathrm{t}_{\mathrm{i}}\right]\right]\right]\right]
$$

Uma projecção funcional acima de VP, Asp (sintagma aspecto), codifica os traços de aktionsart e de diátese do VP, mais concretamente de diátese médio-passiva nos casos em discussão.

Uma análise mais exaustiva, mas na mesma linha, como a que é apresentada em Duarte, Matos e Gonçalves (2001), defende a existência de categorias funcionais específicas para cada subtipo de clítico.

Em ambas as propostas, fica por explicar a razão pela qual os clíticos reflexivos se distribuem por construções tão diversificadas, como as ditas reflexivas ( $O$ João lavou-se.), anticausativas ( $A$ porta abriu-se.) e reflexivas inerentes (A Maria riu-se.). Para não mencionar as impessoais (Vende-se casas.) e passivas (Compraram-se mais carros durante o Verão.) que, como referimos, não estão em discussão no presente trabalho ${ }^{6}$.

\section{A nossa análise}

3.1 Assumpções prévias

3.1.1 O quadro teórico da Morfologia Distribuída (MD)

- Uma análise no quadro da MD remete o contraste verificado para o módulo morfológico, que ocorre pós-sintacticamente.

- A MD assume que nem todas as sequências ou movimentos de constituintes resultam de operações ocorridas exclusivamente na componente sintáctica da gramática.

6 Para uma análise mais detalhada sobre estas construções, veja-se Loureiro (2003). 
- Na Sintaxe são gerados e movidos nós terminais de acordo com princípios sintácticos. O seu resultado vai ser, por sua vez, o input de um domínio morfofonológico, onde ocorrem outras operações que obedecem a princípios próprios. $\mathrm{O}$ que não é constituído na Sintaxe é, portanto, construído depois da Sintaxe, na Morfologia, que compreende uma série de operações que ocorrem no ramo $\mathrm{PF}$, a seguir ao ponto em que a derivação sintáctica se bifurca em PF (forma fonológica) e LF (forma lógica).

- Um morfema é um átomo da representação morfossintáctica; é o nó terminal (sintáctico ou morfológico) e o seu conteúdo, e não a expressão fonológica desse terminal (esta, a expressão fonológica de um morfema, é o expoente, ou parte de um item vocabular).

- O conteúdo de um morfema (abstracto) activo na sintaxe consiste no conjunto de traços sintáctico-semânticos extraídos de um conjunto disponível na Gramática Universal.

3.1.2 O parâmetro de Split, IP, com valor positivo em $\mathrm{PE}$ e negativo em CV

- O parâmetro de Split, IP, proposto em Bobaljik (1995), tem valor positivo em PE (IP domina outras projecções funcionais máximas como TP, AgrP, AspP, etc., e valor negativo em CV (como em Inglês). Em CV, os traços de Acordo (Agr), Modo (Mood) e Aspecto (Asp) são realizados em T (Tempo), sob a forma de um ou mais Itens Vocabulares (IV). Estes são núcleos em sucessiva adjunção, sempre com a etiqueta $T$, com um comportamento idêntico ao dos advérbios (COSTA \& PRATAS 2003, PRATAS 2004).

\subsubsection{Os papéis- $\theta$ como traços}

- A idéia, defendida por Hornstein (1999), de que os papéis- $\theta$ são traços que legitimam o movimento é crucial para a nossa proposta. Esta análise tem por base a rejeição do critério- $\theta$, que proibia o movimento de constituintes de uma posição- $\theta$ para outra. Assumindo esta rejeição, é possível legitimar a ocorrência na frase de DPs com mais de um papel- $\theta$. Como veremos, os dados empíricos sustentam essa hipótese. 


\subsection{A estrutura da frase}

Partindo de Duarte (2001), propomos que a arquitectura da frase do Português inclui um núcleo funcional (Refl, nuns casos, e Caus. ou Voz, noutros casos - e não apenas Asp, como propõe a autora), onde é inserido, no módulo pós-sintáctico, o morfema do tipo se.

Em Caboverdiano, como esta categoria não é projectada, não há lugar para a inserção deste tipo de morfema. Nesse caso, a interpretação da frase depende não só da semântica dos predicados, mas também da sua composição (uma leitura reflexiva, por exemplo, é induzida em CV com certos predicados sempre que não é realizado um argumento interno, excluindo, portanto, a leitura transitiva).

Consideramos que esta nossa proposta permite, por um lado, uma análise unificada para os diferentes tipos de clíticos: argumentais (que deixam de poder ser considerados como tal) e não-argumentais. Passamos assim a considerar não-argumentais todos os clíticos do tipo $s e$. Nos contextos que, dada a improbabilidade de uma leitura reflexiva, requerem em $\mathrm{CV}$ uma expressão anafórica do tipo SELF como em *Pedru mata. / Pedru mata si kabesa., em PE, uma expressão anafórica equivalente (a si mesmol a si próprio) pode ser realizada.

Note-se que a dicotomia entre argumentais e não-argumentais não é clara na literatura. Para Duarte (2001), e.o., os reflexivos inserem-se no grupo dos argumentais (por poderem ser redobrados), enquanto que, para Cinque (1988), por exemplo, são não-argumentais porque não podem sofrer passivização.

Por outro lado, mostramos que diferentes leituras - reflexiva: a) O Pedro lavou-se.; inerente: b) A Ana zangou-se.; ou anticausativainacusativa: c) A porta abriu-se. - são possíveis em Inglês e em CV sempre que esses predicados surgem em entradas aparentemente mono-argumentais. Esta possibilidade deve-se às propriedades internas (semânticas) dos predicados acima, como se pode verificar pelo contraste com, por exemplo, matalmatar/kill, que, em $\mathrm{CV}$ e em Inglês, precisa de uma anáfora do tipo SELF para ter uma leitura reflexiva: Djon mata *(si kabesa); John killed*(himself). 
Grelhas temáticas (sem considerar ainda a posição para o morfema se)

(15) O Pedro lavou-se.

\begin{tabular}{|c|c|}
\hline$\underline{1}$ & $\underline{2}$ \\
AGENTE & $\underline{\text { TEMA }}$ \\
\hline$\underline{i}$ & $\dot{i}$ \\
\hline
\end{tabular}

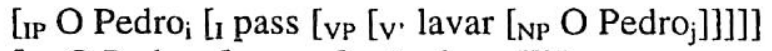

[TP O Pedro ${ }_{\mathrm{ij}}[\mathrm{T}$ pass [VP [v' lavar]]]]

Poderíamos testar a atribuição do papel temático de Agente ao argumento externo do verbo lavar introduzindo na frase, em posição de adjunção, um advérbio orientado para o sujeito Agente, como propositadamente. No entanto, dir-se-ia que esta entrada verbal específica - lavar - contém uma informação inerente dessa noção de intencionalidade: ???O Pedro lavou-se sem querer/acidentalmente. Mas é possível concretizar este mesmo teste com outros verbos transitivos que não contenham a referida informação. É o caso de, por exemplo, sujar: $O$ Pedro sujou-se propositadamente.

Em O Pedro lavou-se. - tal como em O Pedro sujou-se propositadamente. -, o papel temático 1 (argumento externo) e 2 (argumento interno) são acumulados pelo sujeito; estes verbos podem também apresentar entradas transitivas regulares, em que os papéis temáticos são atribuídos a argumentos distintos. Nas entradas reflexivas, porém, a representação semântica mostra que os dois argumentos coincidem: $O$ Pedro $\lambda x$ [x lava $x$ ].

(16) A Ana zangou-se.

\begin{tabular}{|c|c|}
\hline AGENTE $\frac{1}{0 U}$ CAUSA & $\stackrel{2}{2}$ TEMA/PACIENTE \\
\hline$\underline{\mathrm{i}}$ & i \\
\hline
\end{tabular}

LIP $e_{\mathrm{i}}$ [i pass [vp [v' zangar [NP A Ana $\left.\left.\left.\left.\left.\mathrm{j}_{\mathrm{j}}\right]\right]\right]\right]\right]$

[IP A Ana ${ }_{j}\left[\mathrm{I}\right.$ pass [VP zangar [NP $\left.\left.\left.\mathrm{t}_{\mathrm{j}}\right]\right]\right]$ ]

Em A Ana zangou-se., apenas o papel temático 2 é atribuído. Embora não possamos ter uma estrutura de tipo passivo com o verbo zangar (ex.: A Ana foi empurrada. / *A Ana foi zangada.), temos uma 
informação semântica que envolve uma causa ou agente externo não expressos na frase: Fizeram a Ana zangar-se., ou A Ana ficou zangada por/com... Em contextos em que se verifica a realização de um reflexivo inerente, como com verbos do tipo comportar(-se), isto não acontece: o papel temático atribuído é, nesse caso, o 1 , nomeadamente o de Agente.

(17) A porta abriu-se.

\begin{tabular}{|c|c|}
\hline AGENTE $\frac{1}{\text { ou CAUSA }}$ & $\underline{2}$ \\
\hline$\underline{\text { TEMA }}$ \\
\hline
\end{tabular}

[IP $e_{\mathrm{i}}$ [I pass [vp [v' abrir [NP A porta $\left.\left.\left.\left.\mathrm{j}_{\mathrm{j}}\right]\right]\right]\right]$

[IP A porta ${ }_{\mathrm{j}}$ [I pass [vp abrir [NP $\left.\left.\left.\left.\mathrm{t}_{\mathrm{j}}\right]\right]\right]\right]$

Em A porta abriu-se. apenas o papel temático 2 - neste caso o de Tema - é atribuído, com a particularidade de estes predicados, denominados de alternância causativa, terem entradas transitivas correspondentes, com um Agente ou Causa externa realizados: $O$ João abriu a porta. I $O$ vento abriu $a$ porta.

Temos assim as seguintes representações sintácticas, em (18) e (19) para o PE:

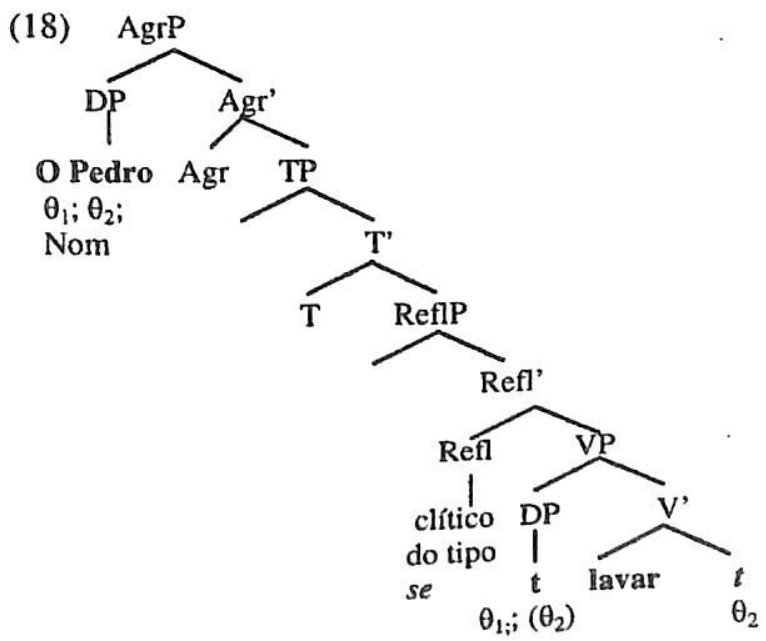


Em (18), $O$ Pedro pode acumular 2 papéis- $\theta$, em aparente violação do Critério- $\theta$, pelo que terá de receber o papel- $\theta$ Tema na sua posição de base (argumento interno), sendo subsequentemente movido (por cópia e apagamento) para a posição de Spec, VP. Aí volta a ser apagado, dado que já existe nessa posição o argumento externo do verbo, com que é co-referente - é, aliás, esta co-referência que permite aquele movimento do argumento interno para uma posição já ocupada por outro DP; esse argumento externo, com papel temático de Agente, recebe / absorve o papel- $\theta$ Tema, o que volta a ser justificado pela co-referência entre os dois argumentos. Dotado de dois papéis- $\theta$, este constituinte move para a posição de Spec, IP, onde recebe Caso nominativo (ao contrário do que propõe Reinhart, não há assim uma redução da valência do verbo, que continua a ser um predicado de dois lugares).

O Caso acusativo pode não ser atribuído, se assumirmos que a sua atribuição ocorreria numa fase posterior da derivação. Em PE, dada a disponibilidade de um núcleo funcional para o efeito, é inserido pós-sintacticamente, na componente morfofonológica da gramática, o clítico do tipo se, um morfema que comporta traços de concordância com o sujeito - pessoa/número - e assume a forma morfológica do Caso acusativo.

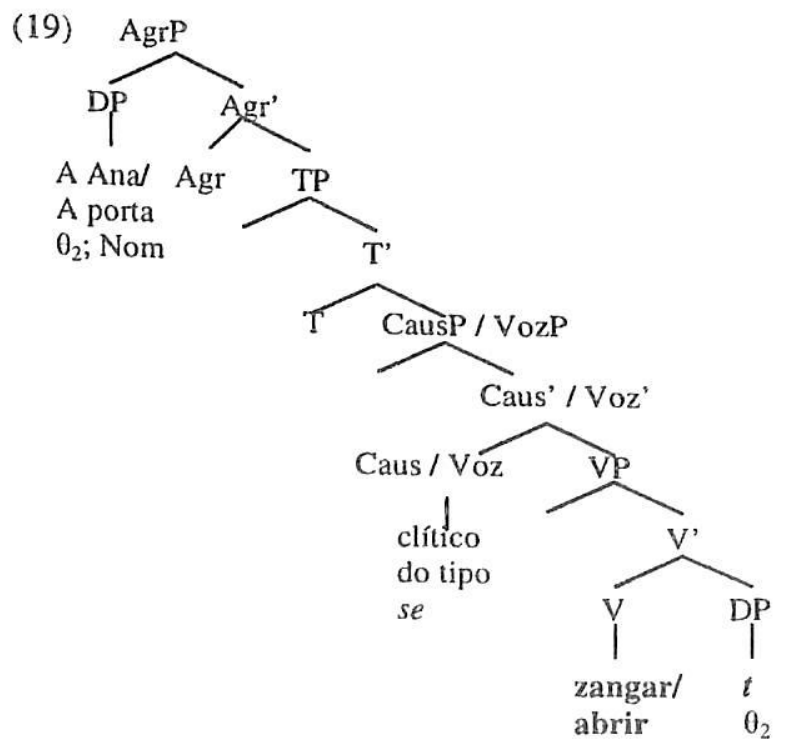


Esta é uma pista para considerarmos que o Caso acusativo em PE é absorvido por este morfema. Quanto aos traços de concordância com o sujeito, é um tópico que teremos de desenvolver posteriormente uma hipótese a explorar será a das possíveis implicações de ele ser inserido num núcleo funcional da frase, dominado por Agr, que em PE tem traços fortes.

Do mesmo modo que no anterior, o clítico (19) do tipo se é um morfema que apresenta traços de concordância com o sujeito e é inserido pós-sintacticamente, na componente morfofonológica da gramática. Ao contrário do que acontece em (18), em (19), não há acumulação de papéis- $\theta$. O papel- $\theta$ interno (Tema, neste caso) é o único atribuído pelo verbo, construindo uma estrutura temática mais próxima de uma passiva (apesar de, por outro lado, um verbo como zangar não ser susceptível de passivização, como vimos anteriormente). E ainda, não há violação do Filtro do Caso: o argumento interno, sem Caso acusativo, é obrigatoriamente movido para a posição de Spec, IP, onde recebe Caso nominativo. Exactamente o que acontece nas estruturas passivas.

Uma análise na perspectiva da semântica composicional mostra que, ao contrário de uma primeira evidência, esta não é uma entrada de tipo inacusativo: semanticamente, temos informações/intuições sobre a relação que é estabelecida pelo predicado, entre o único argumento projectado e ainda uma qualquer causa ou agente (papéis- $\theta$ externos) exteriores não expressos na frase, mas cuja existência é sugerida, precisamente, pelo clítico se.

Para Kayne (1988) e Pesetsky (1995), este clítico assinala a presença na sintaxe do argumento externo, a favor de uma análise inacusativa destas construções. A nossa proposta difere desta, na medida em que o morfema se é inserido pós-sintacticamente, além de que consideramos que o único argumento para apontar estas construções como inacusativas é o de que têm um sujeito derivado.

A comparação com verbos inacusativos, para tentar mostrar um possível contraste, não seria aqui produtiva, uma vez que os testes para tentar "isolar" a inacusatividade não conduzem a resultados idênticos em todos os verbos amplamente considerados inacusativos. Estamos a referir-nos, por exemplo, ao par de contraste: A porta foi aberta. I *A árvore foi caída., em que considerássemos a 
agramaticalidade desta última passivização uma prova da inacusatividade de cair.

Torna-se aqui necessário sublinhar que tentar estabelecer uma tipologia das entradas verbais de acordo com os papéis temáticos atribuídos aos respectivos argumentos é uma tarefa arriscada. Possivelmente, a única afirmação segura a este respeito é a de que as entradas transitivas têm argumento externo (FIÉIS 2003). É o caso de $O$ João abriu a loja. ou de $O$ João abriu a porta. Mas veja-se, por exemplo, que existe uma diferença nos papéis temáticos atribuídos ao argumento interno de duas diferentes entradas do verbo abrir. Partindo do par A loja abriu. / A porta abriu., percebemos que, na primeira frase, de estrutura aparentemente inacusativa - predicado + argumento interno, movido para a posição de sujeito -, não pode (ao contrário do que acontece com a segunda) ser acrescentada qualquer expressão adverbial em adjunção que aponte uma causa externa não intencional ou uma causa interna: *A loja abriu por si só.; *A loja abriu com o temporal. A entrada que aqui consideramos - A porta abriu. - é a que parece corresponder à referida definição de alternância causativa.

Relativamente ao CV, observem-se as seguintes representações, onde verificamos o seguinte: a) a leitura reflexiva em (20) depende do contraste com a estrutura esperada de um verbo transitivo, como em $(21)$; b) a ausência de um DP - que aqui representamos como um vestígio do DP movido por cópia e duplo apagamento (à semelhança do que acontece em PE) - na posição de argumento interno do verbo induz a única interpretação possível: aquela em que o sujeito e objecto da frase coincidem; c) o DP sujeito (co-referente com o DP argumento interno), movido para Spec, TP (a única projecção funcional máxima na arquitectura da frase em CV), recebe Caso nominativo, levando consigo a função temática complexa de Agente + Tema; d) o morfema de reflexividade, do tipo se, não é inserido uma vez que não existe um núcleo funcional disponível para ele e e) quanto ao Caso acusativo, embora não tenhamos nenhuma proposta concreta, é de esperar que não tenha sido atribuído dado não haver um argumento interno foneticamente realizado.

Esta interpretação da frase resulta de uma abordagem composicional (existe um único argumento fonologicamente realizado 
que, em conjugação com a semântica do verbo em questão, induz a leitura reflexiva).

(20)
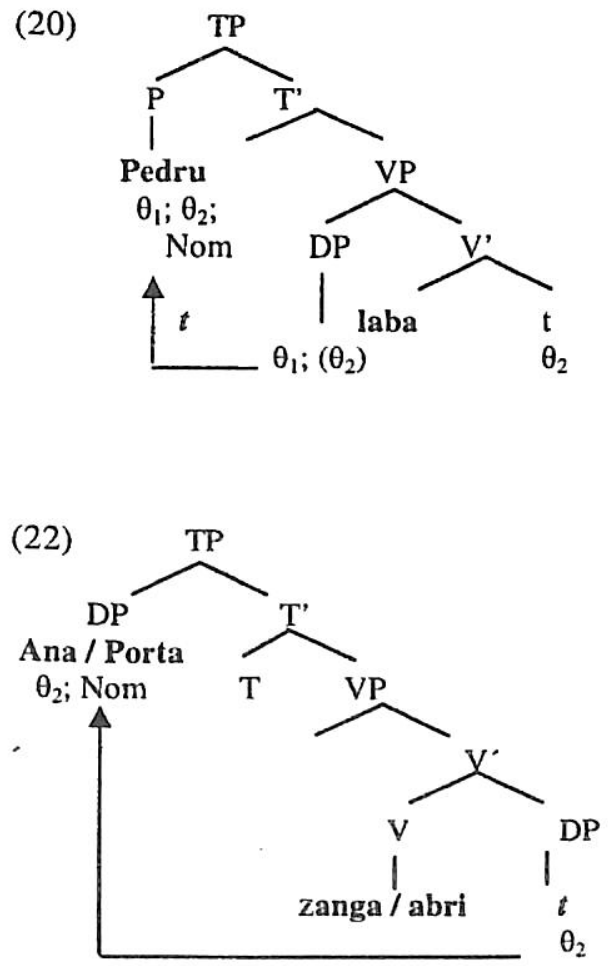
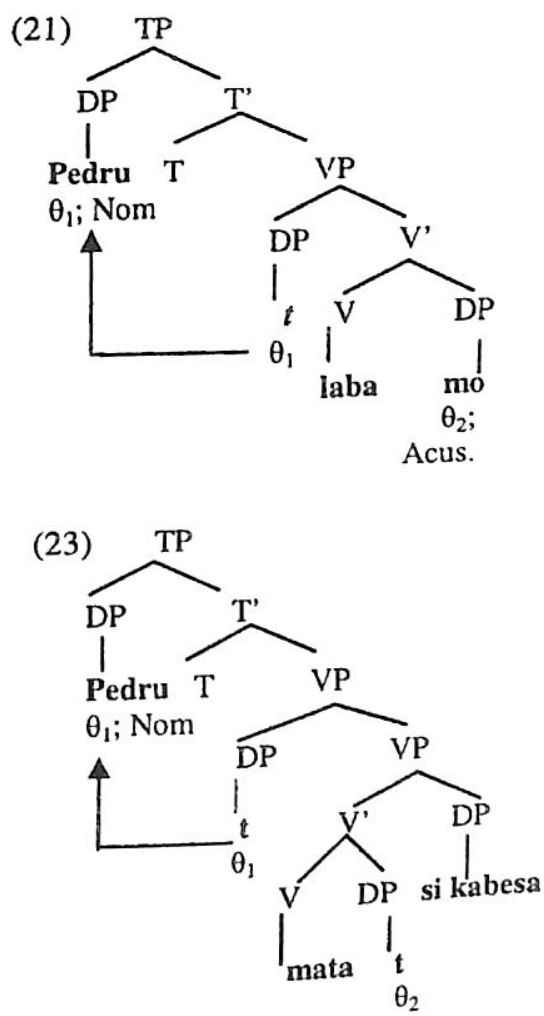

Em (22), o(s) sujeito(s) são gerados na posição de argumento interno, sendo-lhes atribuído o papel temático interno - este difere, no entanto (Tema ou Paciente), conforme a entrada verbal em questão, como aliás seria de esperar. Neste caso, a leitura induzida não é uma reflexiva, uma vez que se assume que, numa entrada reflexiva, o sujeito tem o papel temático de Agente, o que não é o caso. A porta não se abre a si própria (embora possamos dizer A porta abriu-se sozinha.), e se quiséssemos a interpretação de que "A Ana se zangou a si própria.", teria de haver uma expressão anafórica realizada em posição de adjunção, do tipo A Ana zangou-se consigo mesma. 
Em (23), em que a expressão anafórica si kabesa "a si mesmo / a si próprio" é obrigatória em $\mathrm{CV}$, vem comprovar a nossa proposta. Uma vez que a leitura reflexiva está, para o verbo mata "matar" e em $\mathrm{CV}$, no extremo da improbabilidade (se considerarmos uma escala que vai do muito improvável ao muito provável, com alguns graus intermédios) a reflexividade, quando existe, tem de ser explícita. Isto é, não pode ser induzida pela simples ausência de um argumento interno do predicado transitivo, como em (20). Assim, temos realizado um DP adjunto - neste caso uma anáfora -, que reforça a interpretação da frase. Em PE, esta particularidade não se faz sentir para este verbo, uma vez que um morfema do tipo se, inserido pós-sintacticamente no núcleo funcional Refl (sem o reforço da expressão anafórica) é suficiente para uma leitura reflexiva.

\section{Conclusões}

$\checkmark \quad$ Para os predicados aqui em análise, as diferenças entre o $\mathrm{CV}$ e PE não estão na respectiva estrutura argumental. A diferença - que reside na realização, ou não, de um morfema de tipo se -, depende da arquitectura da frase de cada uma destas línguas. Ou seja, estamos aqui perante uma restrição sintáctica: a existência, ou não, de "Split-IP".

$\checkmark$ Os papéis- $\theta$ são traços, o que torna possível a existência de movimento, por cópia e apagamento, de um DP a partir de uma posição- $\theta$ para outra, desde que esta segunda posição seja ocupada por um argumento co-referente com aquele; nesta segunda posição - a de Spec, VP - dá-se um novo apagamento da cópia do constituinte movido - argumento interno -, e a transferência do papel/traço- $\theta$ deste para o sujeito da frase; este processo tem como consequência a acumulação de papéis/traços- $\theta$ no mesmo DP.

$\checkmark \quad$ Esta análise, mesmo a que propomos para o $\mathrm{CV}$, não vai totalmente contra a proposta de Duarte (2001), segundo a qual o morfema se lexicaliza categorias funcionais, independentemente da etiqueta, uma vez que, sendo a estrutura funcional do $\mathrm{CV}$ restrita a $\mathrm{TP}$, não há lugar para os clíticos. 
$\checkmark$ A classificação como inacusativos, como vimos, não parece ser relevante para a análise de alguns predicados, que não obedecem aos testes tradicionais de inacusatividade.

$\checkmark$ Um verbo pode ter apenas uma entrada inacusativa numa língua e poder ser transitivo noutra, como acontece com grow/crescer, que, em inglês, tem uma entrada inacusativa e uma transitiva e, em português ou italiano, tem apenas uma entrada inacusativa (*Eu cresço as flores).

$\checkmark \quad$ Por razões que se prendem com a semântica dos diferentes predicados - e estas propriedades semânticas, como vimos, variam de língua para língua - alguns verbos transitivos, como lavar, permitem a atribuição de papel- $\theta$ interno sem atribuição de Caso acusativo, sem que nenhum outro elemento (por exemplo em adjunção) seja necessário para a gramaticalidade da frase. Porém, com outros predicados, ela é obrigatória, a menos que alguma informação acrescida permita a leitura da frase como reflexiva. Verifique-se o seguinte contraste:

(24)a. *A Maria viu-se.

b. A Maria viu-se a si própria / ao espelho.

Parece-nos que o contraste acima mostra que o se não é argumental, se o fosse não haveria nenhuma razão para que o exemplo (24a) não fosse gramatical.

\section{Referências}

BOBALJIK, J. Mophosyntax: the Syntax of Verbal Inflection. Dissertação de Doutoramento, MIT, 1995.

BOBALJIK, J; THRÁINSSON, H. Two heads aren't always better than one. Syntax, n. 1, v. 1, p. 37-71. 1998.

BURZIO, $\mathbb{L}$. Italian Syntax: A Government-Binding Approach. Dordrecht: Reidel, 1986.

CINQUE, G. On Si Constructions and the Theory of Arb. Linguistic Inquiry, n. 19, v. 4, p. 521-581. 1988. 
COSTA, J; PRATAS,F. Capeverdean Creole: some parametric values. Paper presented at the annual meeting of the ACBLPE, University de A Coruña, Spain, 26-27 Jun. 2003.

CHIERCHIA, G. A Semantics for Unaccusatives and Its Syntactic Consequences. Ms. Cornell University. 1989.

CHOMSKY, N. Lectures on Government and Binding. Dordrecht : Foris, 1981.

CHOMSKY, N. Knowledge of Language: Its Nature Origin and Use New York : Praeger, 1986.

DUARTE, I. Tópicos de Sintaxe Comparada. Relatório para prestação de Provas de Agregação, Universidade de Lisboa, 2001.

DUARTE, I.; MATOS, G.; GONÇALVES, A. Clíticos Especiais em Português Europeu e Brasileiro. Comunicação apresentada ao $2^{\circ}$ Workshop do Projecto "Português Europeu e Brasileiro - Unidade e Diversidade na Viragem do Milénio, Fortaleza, 2001.

DUARTE, I; MATOS, G. Romance Clitics and the Minimalist Program. In: COSTA, J. (Ed.). Portuguese Syntax. New Comparative Studies. New York, Oxford : University Press, 2000. p. 116-142.

EMBICK, D; NOYER, R. Movement Operations after Syntax. Linguistic Inquiry, n. 32, p. 555-595. 2001.

FIÉIS, Maria Alexandra. Ordem de Palavras, Transitividade $e$ Inacusatividade. Reflexão Teórica e Análise do Português dos Séculos XIII a XVI. Dissertação de Doutoramento. Universidade Nova de Lisboa. 2003.

GONÇALVES, A. Predicados Complexos Verbais em Contextos de Infinitivo Não Preposicionado do Português Europeu. Dissertação de Doutoramento. Universidade de Lisboa. 1999.

GRIMSHAW, J. Argument Structure. Cambridge, MA : MIT Press, 1990.

HALLE, M.; MARANTZ, A. Distributed Morphology and the Pieces of Inflection. In: HALE, K.; KEYSER, S. J. (Eds.). The View from Building 20. Cambridge, MA : MIT Press, 1993. p. 111-176.

HORNSTEIN, N. Movement and Control. Linguistic Inquiry, n. 30, p. 69-96. 1999.

KAYNE, R. Romance selsi. GLOW Newsletter 20, 1988. 
LOUREIRO, J. Restrições de Co-ocorrência entre Clíticos Reflexivos e a Morfologia Passiva. Ms. Universidade Nova de Lisboa. 2003.

MARTINS, A. M.; COSTA, J. Clitic Placement across Grammar Components. Comunicação apresentada ao Going Romance, Nijmegen, 2003.

PESETSKY, D. Zero Syntax: Experience and Cascades. Cambridge, MA : MIT Press, 1995.

PRATAS, F. O Sistema Pronominal do Caboverdiano. Variante de Santiago. Dissertação de Mestrado. Universidade Nova de Lisboa, 2002.

PRATAS, F. O Sistema Pronominal do Caboverdiano. Variante de Santiago. Lisboa : Colibri, 2004.

REINHART, T.; REULAND, E. Reflexivity. Linguistic Inquiry, n. 24, p. 657-720. 1993.

REINHART, T. Syntactic Effects of Lexical Operations: Reflexives and Unaccusatives. OTS Working Papers, 1996.

REINHART, T. The Theta System: Syntactic Realization of Verbal Concepts. OTS Working Papers in Linguistics, 2000.

REINHART, T. Experiencing Derivations. SALT lecture, New York, 2001.

THRÁINSSON, H. On the (Non-)universality of Functional Categories. In: ABRAHAM, W. et al. (Eds.). Syntactic Studies in the Minimalist Framework. Amsterdam/ Philadelphia: John Benjamins, 1996. p. 253-281. 